\title{
Formação Inicial Docente e Práticas Pedagógicas Antirracistas: Experiências do PIBID Pedagogia
}

\author{
ALMEIDA, Carla Verônica Albuquerque ${ }^{1}$ \\ GELARD, Fabiana Pedreira ${ }^{2}$
}

\section{RESUMO}

O presente texto apresenta os resultados das práticas pedagógicas desenvolvidas por um grupo de estudantes bolsistas do PIBID do curso de Licenciatura em Pedagogia, da Universidade da Integração Internacional da Lusofonia Afro-Brasileira - campus Malês/BA. Objetiva refletir sobre as experiências formativas desses discentes e a importância de práticas pedagógicas promotoras de uma educação antirracista e de inclusão e valorização das culturas africanas e afro-brasileiras no cotidiano escolar. $O$ subprojeto interdisciplinar Letras e Pedagogia: Educação, Linguagens e práticas pedagógicas: um outro olhar para as identidades étnico-raciais teve como um de seus objetivos o desenvolvimento de atividades voltadas à aplicabilidade das leis 10.639/03 e 11.645/08 com vistas à formação de uma cidadania plena a partir da articulação da Educação para as Relações Étnico-raciais e as Culturas Africana e Afro-brasileira, bem como a promoção de práticas interdisciplinares entre as diferentes áreas do conhecimento, com vista a uma educação antirracista.

Formação Inicial Docente. PIBID. Educação Antirracista.

\section{Initial Teacher Training and Pedagogical Anti-Racists Practices: Experiences of the Institutional Program for Teaching Initiation Scholarships (PIBID) in Pedagogy}

\section{ABSTRACT}

This text presents the results of the pedagogical practices developed by a group of PIBID scholarship students from the Pedagogy Degree course, from the University of International Integration of Afro-Brazilian Lusophony - Malês / BA

\footnotetext{
${ }^{1}$ Doutora em Educação e Contemporaneidade (UNEB). Professora Adjunta da UNILAB Campus dos Malês. Pesquisadora do Grupo de Pesquisa - Família, (Auto) Biografia e Poética (FABEP)/UCSal e Grupo de Estudos em Afrocentricidades (GRUPEAFRO/ UNILAB). E-mail: carlaalmeida@unilab.edu.br. Lattes: http://lattes.cnpq.br/1334298845911044. Orcid: https://orcid.org/0000-0003-2330-1538.

${ }^{2}$ Mestranda no Programa de Mestrado Profissional em Educação e Diversidade, Universidade do Estado da Bahia (UNEB). E-mail: fabianagelard@gmail.com. Lattes: http://lattes.cnpq.br/7909937925395137. Orcid: https://orcid.org/0000-0003-0742-6920.
}

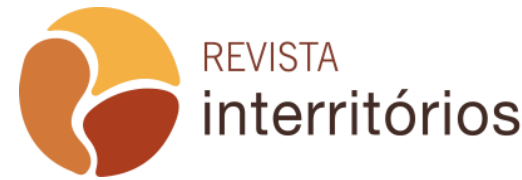


campus. It aims to reflect on the training experiences of these students and the importance of pedagogical practices that promote an anti-racist education and the inclusion and appreciation of African and Afro-Brazilian cultures in school life. The interdisciplinary subproject Letters and Pedagogy: Education, Languages and pedagogical practices: another look at ethnic-racial identities had as one of its objectives the development of activities aimed at the applicability of laws 10.639 / 03 and 11.645 / 08 with a view to the formation of full citizenship based on the articulation of Education for Ethnic-Racial Relations and African and AfroBrazilian Cultures, as well as the promotion of interdisciplinary practices between different areas of knowledge, with a view to anti-racist education.

Initial Teacher Education. PIBID. Anti-racist Education.

\section{Formación inicial docente y prácticas docentes antirracistas: experiencias de la pedagogía PIBID}

\section{RESUMEN}

Este texto presenta los resultados de las prácticas pedagógicas desarrolladas por un grupo de becarios PIBID de la carrera de Pedagogía, en la Universidad de Integración Internacional de la Lusofonia Afrobrasileña - campus Malês/BA. Tiene como objetivo reflexionar sobre las experiencias de formación de estos estudiantes y la importancia de las prácticas pedagógicas que promueven una educación antirracista y la inclusión y valoración de las culturas africanas y afrobrasileñas en la vida escolar. El subproyecto interdisciplinario Letras y Pedagogía: Educación, Idiomas y Prácticas Pedagógicas: otra mirada a las identidades étnico-raciales tuvo como uno de sus objetivos el desarrollo de actividades encaminadas a la aplicabilidad de las leyes 10.639 / 03 y 11.645 / 08 con miras a la formación de ciudadanía plena basada en la articulación de la Educación para las Relaciones Étnico-Raciales y las Culturas Africanas y Afrobrasileñas, así como la promoción de prácticas interdisciplinarias entre las diferentes áreas del conocimiento, con miras a la educación antirracista.

Formación Docente Inicial. PIBID. Educación Antirracista.

\section{Formazione iniziale degli insegnanti e pratiche pedagogiche antirazziste: esperienze di pedagogia PIBID}

\section{SOMMARIO}

Questo testo presenta i risultati delle pratiche pedagogiche sviluppate da un gruppo di studenti con borsa di studio PIBID del corso di laurea in pedagogia, presso l'Università di integrazione internazionale della lusofonia afro-brasiliana campus di Malês/BA. Ha lo scopo di riflettere sulle esperienze formative di questi studenti e sullimportanza delle pratiche pedagogiche che promuovono un'educazione antirazzista e l'inclusione e l'apprezzamento delle culture africane e afro-brasiliane nella vita scolastica. II sottoprogetto interdisciplinare Lettere e Pedagogia: Educazione, Lingue e pratiche pedagogiche: un altro sguardo alle 
identità etnico-razziali aveva come obiettivo lo sviluppo di attività finalizzate all'applicabilità delle leggi 10.639 / 03 e 11.645 / 08 in vista della formazione cittadinanza piena basata sull'articolazione dell'educazione alle relazioni etnicorazziali e culture africane e afro-brasiliane, nonché la promozione di pratiche interdisciplinari tra diverse aree di conoscenza, in un'ottica di educazione antirazzista.

Formazione iniziale degli insegnanti. PIBID. Educazione antirazzista.

\section{INTRODUÇÃO}

A caminhada de formação docente é contínua e desafiadora, permeada por expectativas, sentimentos e experiências que vão constituindo os saberes e práticas na trajetória docente. E neste caminhar...alternativas abrem janelas, descortinam desafios, criam espaço onde o professor tenha assegurada e sua fala, onde o seu fazer pedagógico se presentifique por meio de diferentes linguagens, pelas experiências e aprendizagens adquiridas no decorrer do percurso de vida. Uma vez que vez que é pelo "[...] desenvolvimento de um saber sobre as suas qualidades e competências que o educando pode tornar-se sujeito da sua formação" (JOSSO, 2004, p. 49). Nesta perspectiva, a formação vai se delineando a partir das experiências iniciais docentes e vai se construindo ao longo de uma trajetória acadêmica-profissional, caracterizando-se como um momento de crescimento, de aperfeiçoamento, no qual o caminho percorrido se torna essencial e indispensável para a concretização do seu fazer e ser profissional.

A formação é um processo de transformação em que as relações são tecidas por uma complexidade de fios que estabelecemos com o mundo, com os nossos pares e conosco mesmo, em um entrelaçamento de dimensões pessoais e profissionais, por meio de saberes múltiplos, desafios constantes, afetos e afetações intensas, em um cenário onde as relações são tecidas, formando uma ressonância entre as diferentes experiências vividas que nos constituem professor(a).

Para Tardif (2008), a atividade docente é realizada em uma rede de interações com outros sujeitos mediados por discursos, comportamentos, maneiras de ser que vão sendo incorporadas a sua prática. Saberes que devem estar "[...] em íntima relação com o que os professores, nos espaços de trabalho cotidiano, são, fazem, pensam e dizem" (p. 18). Dessa forma, torna-se fundante considerar a diversidade de aspectos que permeiam a prática docente numa postura reflexiva, questionadora e dialógica, com estímulo à investigação e atitudes colaborativas, frente aos processos de construção do conhecimento, que caminhe na contramão de uma formação alienante e reprodutora.

Uma formação que reverbere em experiências que possam ir além da natureza instrumental e meramente técnica e acadêmica, que se constitua "[...]

\begin{tabular}{l|l} 
REVISTA & Interritórios | Revista de Educação \\
interritórios & Universidade Federal de Pernambuco, \\
Caruaru, BRASIL | V.6 N.12 [2020]
\end{tabular}


num amálgama de vontades de produzir um outro tipo de conhecimento, mais próximo das realidades educativas e do quotidiano dos professores" (NÓVOA, 1995, p. 19); uma prática pedagógica expressiva que considere a diversidade e subjetividade dos sujeitos implicados.

Neste contexto, torna-se fundante possibilitar às futuras professoras e aos futuros professores um conjunto de saberes abrangentes, didáticos e transversais, provenientes da sua formação inicial e contínua que possibilite

[...] a sua capacidade de informação crítica, habilitado a ler e a interpretar a sua realidade e seu entorno; capacidade de atualização incessante, sobre o fulcro do 'aprender a aprender', num esforço sempre renovado de não ceder à instrumentalização subalterna. (DEMO, 2009, p. 30).

A atitude dialética, crítica e reflexiva são basilares a formação que assegure o diálogo teoria e prática amalgamados no processo ensino e aprendizagem.

Consideramos que a docência deve ser uma atividade realizada além do que é prescrito e nesse sentido, em constantes questionamentos que inquietem e mobilizem professoras e professores a investigação, possibilitando dar significado e sentido a suas ações. Assim, urge romper com o paradigma conservador

na busca de formar estudantes/professores reflexivos, que saibam lidar com as incertezas, as singularidades, os conflitos colocados em pauta pela diversidade cultural, pelas inovações tecnológicas, pela velocidade da informação, pela afirmação das identidades. (SILVA; ALMEIDA; JESUS, 2014, p. 5).

Atitude a ser assumida pelas licenciaturas na formação inicial de professoras e professores, o que requer, das IES fomentar reflexões críticas sobre suas concepções, atitudes, práticas e comportamentos, relacionando aspectos teóricos e metodológicos voltados a ação docente, consubstanciando a articulação entre educação superior e educação básica, na perspectiva de integração de propostas e projetos de formação.

É neste cenário que se insere o Programa de Iniciação a Docência - PIBID - criado no final de 2007 pela Coordenação de Aperfeiçoamento de Pessoal de Nível Superior (CAPES) e regulamentado pelo Decreto no 7.219 , de 24 de junho de 2010, tornando-se uma política pública de formação de professores. Dentre os seus objetivos, apontados no Art. $3^{\circ}$, destacamos: 
I - incentivar a formação de docentes em nível superior para a educação básica;

II - contribuir para a valorização do magistério;

III - elevar a qualidade da formação inicial de professores nos cursos de licenciatura, promovendo a integração entre educação superior e educação básica;

IV - inserir os licenciandos no cotidiano de escolas da rede pública de educação, proporcionando-Ihes oportunidades de criação e participação em experiências metodológicas, tecnológicas e práticas docentes de caráter inovador e interdisciplinar que busquem a superação de problemas identificados no processo de ensino-aprendizagem;

V - incentivar escolas públicas de educação básica, mobilizando seus professores como co-formadores dos futuros docentes e tornando-os protagonistas nos processos de formação inicial para o magistério;

VI - contribuir para a articulação entre teoria e prática necessárias à formação dos docentes, elevando a qualidade das ações acadêmicas nos cursos de licenciatura. (BRASIL, 2010).

Ao possibilitar a ampliação do processo de formação docente, aproximando as futuras professoras e professores das dinâmicas da educação básica, permitindo a construção e mobilização de saberes e práticas pedagógicas que dialoguem com o ambiente e o cotidiano escolar da rede pública, o PIBID contribui de maneira significativa "para a compreensão global e dimensional da educação e da profissão docente, ainda no momento da formação inicial" (DEIMLING; REALI, 2020, p. 5). Neste contexto, cabe salientar que a instituição escolar é um importante lócus de materialização das políticas educacionais; e nesse sentido, requer uma reflexão sobre as demandas e necessidades que se presentificam no 'chão da escola', as quais nem sempre são visibilizadas/atendidas. O que exige repensar concepções e práticas pedagógicas simplistas e fragmentadas, tecendo relações ancoradas nas teorias que alicerçam o processo formativo e dos saberes pessoais e da experiência, de forma imbricada e não dicotômica.

$\mathrm{Na}$ esteira desta discussão, as Diretrizes Curriculares propostas pela Lei de Diretrizes e Bases da Educação Nacional - LDBEN 9394/96 para a formação docente, a escola deverá ser concebida como espaço que tem função social e formativa, onde os saberes construídos a partir da multiplicidade de conhecimentos otimizados, deverão articular-se com o exercício profissional, alicerçado na formação, participação e experiência, constituindo-se como "uma preparação voltada para o atendimento das demandas de um exercício profissional específico que não seja uma formação genérica e nem apenas acadêmica" (BRASIL, 2001, p. 29), mas direcionada às exigências advindas das demandas socioculturais próprias de uma sociedade em constante processo de mudança. 
Cabe salientar que enquanto estudante de licenciatura, a experiência proporcionada pelo PIBID junto a estudantes, professoras e professores da educação básica em exercício da função, é crucial ao processo formativo de futuras professoras e professores, sobretudo na disseminação e troca de saberes e nas práticas pedagógicas metodológicas que alicerçarão a própria experiência individual e coletiva. Um movimento que "[...] Vai e vem, avança e recua, construindo-se num processo de relações ao saber e ao conhecimento, que permitem intervir no desenvolvimento do ensino, do currículo e da escola" (NÓVOA, 2011, p. 58). Um processo de ação-reflexão-ação, onde os saberes são postos em prática, juntamente com novos saberes que são incorporados aos antigos, com vistas à materialização de uma prática pedagógica que entrelace elementos teóricos com situações práticas reais.

$\mathrm{Na}$ tessitura dessas reflexões, o presente texto objetiva refletir sobre as experiências formativas de um grupo de estudantes bolsistas do PIBID, do Curso de Licenciatura em Pedagogia da Universidade da Integração Internacional da Lusofonia Afro-Brasileira - UNILAB - e a importância de práticas pedagógicas promotoras de uma educação antirracista e de inclusão e valorização das culturas africanas e afro-brasileiras no cotidiano escolar.

Destarte, o desenvolvimento do subprojeto Educação, Linguagens, práticas pedagógicas: um outro olhar para as identidades étnico-raciais, possibilitou a aplicabilidade da Lei 10.639/03, bem como integrar estudantes com a comunidade do Recôncavo baiano, um leque de experiências escolares e extra escolares que enriqueceram sua formação pedagógica.

\section{A Lei 10.639/03: reflexões para uma educação antirracista}

Refletir sobre a prática pedagógica a partir de sujeitos diversos e oriundos de distintos lugares sociais e culturais, torna-se fundante para a compreensão da cultura afro-brasileira e africana nas suas diásporas, na construção de uma educação que engendre saberes e práticas identitárias e emancipatórias que se desenvolvam na contramão "do mito da democracia racial que paira sobre 0 imaginário da grande maioria dos professores" (MUNANGA, 2005, p. 63). Uma vez que o que presenciamos é um processo de "inclusão excludente", em um contexto de dinâmicas e ações que são criadas e recriadas, que se expressam de forma errônea e arquetipicamente ideológica. Inócuas para reverter as condições de negação e segregação, em prol de práticas antirracistas.

O silenciamento e a marginalização das culturas consideradas inferiores, a exemplo da cultura negra, pela cultura hegemônica europeia, é reforçada no ambiente escolar, ao ceder espaço para formulações racistas e preconceituosas que naturalizaram as desigualdades, reforçando a construção de estereótipos em torno de suas imagens. Neste cenário, é premente uma formação que 
possibilite o desenvolvimento de uma educação e consequentemente de uma prática pedagógica que transponha limites com vistas a transmitir, ampliar e visibilizar os valores e saberes afrodescendentes, considerando histórias e identidades étnico-raciais, como aspectos fundantes que articulem as condições materiais às dinâmicas sociais, culturais, identitárias, políticas e equitárias.

Nesta esteira, um dos maiores desafios para os profissionais da educação é dar materialidade a uma prática docente que trate pedagogicamente as diferenças de forma equitativa e respeitosa. A implementação da Lei 10.639/03 (atualizada pela Lei $11.645 / 08$ ), enquanto política pública, busca romper as desigualdades acumuladas historicamente, dirimindo posturas pedagógicas que não reconhecem as diferenças resultantes do processo de formação do povo brasileiro de matriz africana, garantindo mais igualdade de tratamento e de oportunidade, compensando perdas provocadas pela discriminação e pela marginalização. "[...] um ponto de chegada de uma luta histórica da população negra para se ver retratada com o mesmo valor dos outros povos que para aqui vieram, e um ponto de partida para uma mudança social" (UNESCO; MEC, 2008, p.10).

A Lei $10.639 / 03^{3}$ foi sancionada no ano de 2003 e insere o artigo 26-A na Lei de Diretrizes e Bases (LDB) - LEl 9394/2006 - tornando obrigatório o ensino da história e cultura afro-brasileira no Ensino Fundamental e no Ensino Médio, em escolas públicas e privadas. Os conteúdos deverão ser ministrados no âmbito de todo o currículo escolar, em especial nas áreas de educação artística e de literatura e história brasileira. A partir do artigo 79-B a LDB passa a incluir no calendário escolar o dia 20 de Novembro como o Dia da Consciência Negra.

A lei é resultado de lutas históricas dos Movimentos Negros, sobretudo dos esforços engendrados no campo da educação. Podemos destacar como marco a participação do Movimento Negro na III Conferência Mundial para o Racismo, a Discriminação Racial, a Xenofobia e Formas Correlatas, organizada e promovida pela Organização das Nações Unidas no ano de 2001 em Durban, na África do Sul. Momento em que o Brasil passa a ser signatário do Plano de Ação de Durban e reconhece a existência do racismo institucional no Estado brasileiro e se compromete a construir medidas para a superação, dentre as quais políticas de ações afirmativas. (GOMES, 2018).

Outro marco a ser destacado na abertura de diálogo entre o Estado Brasileiro e o Movimento negro no campo da educação é a criação da Secretaria de Educação Continuada, Alfabetização e Diversidade (SECAD), o que contribuiu para que as reivindicações dos movimentos sociais ganhassem visibilidade dentro do Ministério da Educação (GOMES, 2018). Desse

\footnotetext{
${ }^{3} \mathrm{Em} 2008$ a lei 11.645/08 modifica o artigo 26-A incluindo a obrigatoriedade da história e cultura indígena nos currículos nacionais. Contudo, por uma escolha política, neste artigo trataremos da Lei 10.639/03. 
movimento e como forma de orientar a implementação da Lei 10.639/03 dá-se a criação das Diretrizes Curriculares Nacionais para a Educação das Relações Étnico-raciais e para o Ensino da História e Cultura Afro-brasileira e Africana, em 2004 e do Plano Nacional de Implementação das Diretrizes Curriculares Nacionais, em 2009.

As Diretrizes têm por objetivo o reconhecimento e a valorização da identidade, da história e da cultura afro-brasileira, bem como das raízes africanas que conformam a cultura brasileira. Além disso, objetivam a produção de conhecimento e de atitudes, posturas e valores para a pluralidade étnico-racial, garantindo a valorização da identidade das pessoas afro-brasileiras na busca da consolidação da democracia no país. Para tanto,

\begin{abstract}
Caberá, aos sistemas de ensino, às mantenedoras, à coordenação pedagógica dos estabelecimentos de ensino e aos professores, com base neste parecer, estabelecer conteúdos de ensino, unidades de estudos, projetos e programas, abrangendo os diferentes componentes curriculares. Caberá, aos administradores dos sistemas de ensino e das mantenedoras prover as escolas, seus professores e alunos de material bibliográfico e de outros materiais didáticos, além de acompanhar os trabalhos desenvolvidos, a fim de evitar que questões tão complexas, muito pouco tratadas, tanto na formação inicial como continuada de professores, sejam abordadas de maneira resumida, incompleta, com erros. (BRASIL, 2004).
\end{abstract}

De forma a fortalecer e institucionalizar a Lei 10.639/03 e as Diretrizes decorrentes, o Plano Nacional de Implementação das Diretrizes (BRASIL, 2009 $\mathrm{s} / \mathrm{p}$ ) elencam uma série de ações a serem tomadas, dentre elas uma política de Formação Inicial e Continuada; uma política de material didático e paradidático; avaliação e monitoramento; condições institucionais para avaliação dos aspectos organizacionais.

Para Silva (2019), a Lei 10.639/03 enquanto uma política curricular questiona o modelo único de escola e a seleção e hierarquização de conhecimentos, bem como a homogeneização de culturas e identidades. Assim propõe a modificação da instituição escolar desde sua estrutura, exigindo mudanças de atitudes e abertura da escola à outros conhecimentos. Assim, a obrigatoriedade do ensino da história e cultura afro-brasileira deu origem a uma série de processos de ações educativas em diversos níveis de ensino de forma a possibilitar a inclusão da temática nos currículos das escolas brasileiras. Contudo, destaca que os currículos construídos em sala de aula transitam entre a obrigatoriedade da lei, aquilo que professoras e professores sabem, e aquilo que acreditam. Nesse processo, a formação docente ganha papel relevante, uma vez que 
[...] o desafio de contar e aprender uma história outra e fazer dela um elemento de novas perspectivas políticas, epistemológicas e identitárias nos processos educacionais (OLIVEIRA, 2011, p.11).

[...] não está mais apenas a cargo dos movimentos negros, mas de todos os profissionais da educação. Todavia, concordamos com o autor: esse continua sendo um campo de disputas, conflitos e negociações. (SILVA, 2019, p. 33).

Nesse sentido, somos contrárias à ideia de implementação da lei como algo pronto e acabado que deve ser instituído tal e qual a letra da Lei no cotidiano da escola. Acreditamos, ao contrário, que as escolas, bem como as profissionais e os profissionais da educação interpretam e traduzem as leis, atuando-as nas escolas a partir de um movimento criativo (BALL, 2016). Essa complexificação nos ajuda a entender porque depois de 17 anos de instituição da Lei 10.639/03 ainda encontramos resistência e ações que apresentam poucos resultados efetivos na superação do racismo. Uma vez que ao chegarem à escola, estes documentos são lidos, interpretados e traduzidos, e a partir de processos de escolhas as atuações são realizadas. Assim, não cabe dizer que a lei é ou não implementada, mas entender que o que está posto na escola, a forma como esta instituição lida com a cultura afro-brasileira, é, exatamente, o reflexo das escolhas das atrizes e dos atores que a constituem.

Ao refletirmos historicamente sobre a sociedade brasileira, sem muito esforço veremos que foram mais de 400 anos de processos de escravização de corpos africanos e apenas 131 anos de República no Brasil. O que nos conduz a pensar que a referida sociedade ainda se estrutura a partir de uma lógica escravocrata e que o ranço colonial ainda organiza as relações sociais. A colonialidade 4 do ser/saber, entendida enquanto o legado colonial presentificado na contemporaneidade e que impõe um pensamento único, uma forma única de existência humana baseada em valores eurocêntricos, relega as culturas afrobrasileiras, africanas e indígenas à marginalização na sociedade de maneira geral e na escola em específico.

Atualmente, dada a obrigatoriedade da Lei 10.639/03, tais culturas se manifestam nos currículos escolares muitas vezes em uma perspectiva ainda folclorizada, tendo espaço em momentos como o Dia do Folclore e o mês da consciência negra, o Novembro Negro, em alusão ao dia 20 de Novembro, dia de morte de Zumbi dos Palmares e que ficou marcado como Dia da Consciência Negra. O que se vê são reproduções muitas vezes estereotipadas e que giram

\footnotetext{
${ }^{4}$ Entendemos a colonialidade como o legado colonial ainda presente nas sociedade que outrora viveram sob o jugo colonial. Ela se manifesta nas relações sociais, na construção do

conhecimento, na organização política, nas práticas educativas, etc. 
em torno apenas da estética e das manifestações artísticas e esportivas. Contribuindo para a perpetuação de preconceitos acerca dos corpos negros.

Petit (2015) aponta a necessidade de pessoas negras se apropriarem da negritude e para tanto é necessário um senso de pertencimento à ancestralidade africana, "[...] algo que só é possível tocando no sentimento das pessoas, elas precisam sentir-se negras, esse sentimento é transmitido principalmente pelo nosso corpo, pois ele é o guardião da nossa memória ancestral" (PETIT, 2015, p. 148). Contudo, é necessário destacar que a materialização de ações antirracistas e de valorização da ancestralidade africana e da cultura afrobrasileira não pode somente dizer respeito às professoras negras e professores negros, faz premente que pessoas brancas, reconheçam os processos racistas de formação da sociedade e atuem dando materialidade as ações.

Diante da necessidade de formação de professoras e professores e valorização do pertencimento étnico racial de pessoas negras, bem como o reconhecimento das raízes afroancestrais que nos compõem, Petit et al (2015), cunha o termo Pretagogia como um referencial teórico-metodológico para a formação de professoras e professores que se nutrem de saberes, conhecimentos e valores de matriz africana.

\begin{abstract}
Além das práticas corporais e artísticas, a Pretagogia incentiva a relação comunidade-escola, chamando mestres e mestras da cultura para dentro dos recintos educacionais, bem como a saída para locais-recurso, ou seja, espaços que se aproximem da compreensão da cosmovisão africana, desde áreas naturais, ao ar livre, até sedes de entidades de praticantes das culturas tradicionais (vistos como pessoas-recursos). (PETIT, 2015, p. 125).
\end{abstract}

A autora prossegue chamando a atenção para a necessidade de desenvolvimento de intervenções pedagógicas que contribuam deliberadamente para mudanças de posturas, com recursos direcionados para apropriação da cosmovisão africana. Outrossim, estratégias voltadas as dimensões subjetivas de opressão, com referenciais teórico-metodológicos focados nos "valores das culturas africanas, articulando-os à transdisciplinaridade e à transposição didática, de forma que os saberes/ conhecimentos ginguem entre si e produzam novas práticas, num fluxo constante, enlaçadas pela circularidade" (ALVES, 2015 , p. 477) de saberes afrorreferenciados como elementos que alicercem as experiências de ensino-aprendizagem.

Há de se registrar que a exigência de novos paradigmas e práticas pedagógicas educacionais, especialmente no tocante à formação inicial de professores no trato com a diferença e a diversidade destaca-se nas discussões sobre a necessária reformulação das políticas de formação de professores no Brasil. Nesta perspectiva, a Universidade da Integração Internacional da 
Lusofonia Afro-Brasileira (UNILAB), criada em 2008, busca dentre os seus objetivos a materialização da Lei 10.639/2003, tendo por base um currículo expandido pelos movimentos sociais africanos, brasileiros e afrodiaspóricos; 0 que reverbera na formação de profissionais que possam se comprometer com a disseminação da cosmovisão africana e afro-brasileira em suas práticas profissionais. Que considere "outras presenças, respeite a diversidade, oportunize o direito à história; [...] que contemple os sujeitos em suas diferenças, sem acepções e inferiorizações" (CANDAU, 2012, p. 26), transpondo limites com vistas a construir, ampliar e visibilizar diferentes saberes e dinâmicas sociais, culturais, identitárias e políticas.

\section{Subprojeto Pedagogia Malês: caminhos trilhados}

O subprojeto Educação, Linguagens, práticas pedagógicas: um outro olhar para as identidades étnico-raciais é vinculado aos cursos das Licenciaturas em Letras e Pedagogia dos Malês/UNILAB; ambos, em sua essência, têm como marca a produção e disseminação de conhecimento, na perspectiva de uma epistemologia da África e de suas diásporas, antirracismo e anticolonial, promotora da efetiva valorização dos saberes científicos e ancestrais. De acordo com o Projeto Institucional do PIBID/UNILAB, a inserção de tal temática, na perspectiva interdisciplinar na prática cotidiana de seu processo formativo, nas escolas da educação básica, certamente, ampliará seu escopo teóricometodológico para as suas ações educativas (CAPES, 2018).

Nesta perspectiva, ancoramos este estudo na abordagem qualitativa caracterizada por apresentar, segundo Bogdan e Biklen (1994), a fonte direta dos dados, tendo como principal agente o pesquisador, o ambiente natural, interessando-se mais pelo processo do que pelo produto e acima de tudo, por tentar compreender o significado que as/os participantes atribuem às suas experiências, inclusive as que emergem subjetivamente. $O$ enfoque metodológico alicerçou-se em observações, coparticipação nas ações promovidas nas escolas contempladas pelo projeto e atividades planejadas e desenvolvidas pelos bolsistas com as crianças dos anos iniciais do Ensino Fundamental.

O subprojeto foi desenvolvido no município de São Francisco do Conde BA, localizado na região do Recôncavo Baiano, caracterizado por uma população pluriétnica e pluricultural; nos quais há uma rede pública conveniada com a Universidade da Integração Internacional da Lusofonia Afro Brasileira Campo dos Malês. Como participantes na área de Pedagogia, contou com vinte estudantes, bolsistas do PIBID, os quais desenvolveram as atividades em duas escolas municipais, com crianças dos anos que tiveram contato com a diversidade dos contextos educacionais do município de São Francisco do 
Conde - BA, o convívio com o ambiente escolar, suas dinâmicas, arquitetura pedagógica e administrativa e, junto com duas professoras bolsistas supervisoras e a coordenadora de área, formularam estratégias pedagógicas voltadas à valorização da diversidade étnico-racial, como estratégia para uma educação antirracista.

A região abriga uma riqueza singular herdada das tradições culturais decorrentes do contato entre os povos originários, africanos escravizados e portugueses colonizadores, o que resultou em formas de expressão que particularizam os costumes, os valores, as crenças, práticas culturais e os hábitos regionais; patrimônios que evidenciam o rico universo cultural dos afrodescendentes. Durante o período escravocrata, a região, então organizada a partir de engenhos de açúcar e pequenas vilas, foi palco de muitos levantes contra a escravização, protagonizados por africanos e afrodescendentes que aqui viviam. Historicamente, a região protagonizou múltiplas formas de resistência, rebeliões, fugas e negociações nas soluções de luta pela libertação do regime escravocrata.

Apesar da importância histórica e da riqueza cultural, no entanto, a vulnerabilidade social da população que constitui a região é visível ao observador atento e os índices atestam para tal. Se considerarmos que a maioria da população da região é constituída por negros (agregado autodeclarados "pretos" e "pardos"), esta realidade afeta diretamente essa população, especialmente as crianças e os jovens que caracterizam a maior parte dos habitantes da região. Hoje, portanto, essa população vivencia ainda as consequências das vulnerabilidades históricas herdadas do regime escravocrata.

Em um cenário constituído por disparidades e exclusões étnicas, torna-se fundante viabilizar propostas curriculares educativas e projetos, voltados para a valorização da cultura negra, garantindo o respeito a diversidade cultural, articuladas ao processo ensino-aprendizagem, referenciados na realidade local e nacional, possibilitando a desconstrução de práticas preconceituosas, com vistas a contribuir para mudanças nesse quadro, considerando a formação de crianças e jovens, bem como de profissionais que atuam e dos que poderão atuar na área da educação. Nessa perspectiva, elegemos o trabalho com práticas pedagógicas antirracistas como foco principal das nossas ações.

Antes de iniciarem as atividades, porém, o grupo de discentes aproximouse da escola, estudou os documentos, a história, o projeto pedagógico da escola, conversou com direção, com professoras e professores, alunas e alunos, técnicos e comunidade familiar do bairro, realizando um estudo etnográfico de toda a comunidade dentro e ao redor da escola.

Observaram inicialmente a estrutura da escola, a prática pedagógica desenvolvida pelas professoras regentes em sala de aula, os recursos disponíveis e as metodologias utilizadas. Assim como, conhecerem quais 
culturas e saberes locais estavam ou não, sendo percebidos pela escola e trabalhados com as crianças. $O$ que se constituiu em momentos importantes para avaliação e reflexão sobre o trabalho desenvolvido, assim como para o planejamento das atividades e ações didático-pedagógicas futuras.

\section{Nos relatos das experiências, a busca de práticas pedagógicas antirracistas}

Foram muitas as inquietações que suscitaram reflexões sobre os desafios da experiência docente que se iniciava para os(as) estudantes bolsistas: como um município com uma população majoritariamente negra, dá maior visibilidade as representações embranquecidas? Por que a escola reforça estas representações e silencia a imagem do negro? Como a criança negra pode aceitar o seu grupo étnico, se a sociedade dita padrões e espaços inferiores para o negro? De que maneira esses estereótipos podem influenciar na construção da identidade da criança negra?

O desafio estava posto e neste contexto, as bolsistas e os bolsistas observaram que a cultura africana e afro-brasileira, eram até então pouco exploradas na escola, posto que os professores regentes, via de regra, tinham referências mínimas diante de tais temáticas no currículo praticado. $O$ que denota um certo silenciamento no espaço escolar frente a importância de ações continuadas para que o fortalecimento dessas culturas, previsto na lei, seja realizado de maneira efetiva e não pontual.

As realidades observadas foram objetos de discussão nos encontros mensais realizados entre a coordenação do projeto, as supervisoras de área e o grupo de bolsistas, levando-as/os a pensar em estratégias e atividades que contemplassem aspectos culturais, sociais, identitários, das educandas e dos educandos dos anos iniciais do Ensino Fundamental, bem como mobilizassem discussões sobre racismo, preconceito, identidade, diversidade, diferenças, a partir de atividades diversificadas, tais como: oficinas artísticas em diversas expressões como desenhos, dança, música, teatro; contação de história; exibição de filme; jogos, entre outros.

Para Oliveira (2007, p. 21) "planejar é pensar sobre aquilo que existe, sobre o que se quer alcançar, com que meios se pretende agir". Assim, seja de forma individual, em dupla e/ou em coparticipação com a professora regente, as atividades a serem aplicadas com os(as) educandos(as), no processo ensino e aprendizagem, foram fundantes e se constituíram como oportunidade para estimular a autonomia, rever crenças, compreender limites e desafios que se descortinavam no campo de atuação docente. 
Uma das primeiras ações desenvolvidas por parte das estudantes bolsistas foi a exibição do filme moçambicano Phatyma, uma atividade diagnóstica proposta por uma das estudantes bolsistas como forma de conhecer quem eram as estudantes e os estudantes e qual sua percepção de si. Para tanto, dentre as propostas posteriores à exibição do filme estava a escrita de uma autobiografia e o desenho de um autorretrato. Da atividade de autorretrato destacam-se duas: a imagem construída por uma estudante negra que se desenhou como uma menina loira e ao ser questionada se aquela era ela, a estudante apenas assentiu com a cabeça; uma outra estudante negra conseguia se desenhar, dizia não saber, se achar feia, entregou um desenho de si apenas no traço do lápis, sem colorir. Ela era uma das meninas mais velhas da turma, alta, gordinha. A mesma estudante relatou em sua biografia histórias da sua vida que, segundo ela, não havia contado para ninguém e pediu que fosse mantido segredo sobre o que estava escrito.

Segundo Gomes (2002) o corpo fala do nosso estar no mundo, as diferentes crenças e sentimentos que organizam a vida em sociedade são aplicadas ao corpo. Isso significa dizer que a cultura é organizada de forma a exaltar ou inibir determinadas características, sentimentos e impulsos, ditando normas em relação ao corpo a partir das quais as pessoas deverão conformarse até o ponto que tais ordenamentos estarão naturalizados.

A existência de um padrão de beleza que prima pela "brancura", numa sociedade miscigenada como a nossa, afeta ou não a nossa vida nas diferentes instituições sociais em que vivemos? Essas representações estão presentes na escola? Como? (GOMES, 2002, p. 42).

As imagens produzidas pelas estudantes demonstram o quanto o corpo negro é regulado e estereotipado "por um conjunto de representações que sustentam os ideais de beleza corporal branca, eurocentrada e, no limite, miscigenada em contraposição a pele preta." (GOMES, 2018, p. 96). No entanto, não foi somente a negação ao corpo negro feminino que figurou nas atividades, a maioria das crianças desenharam uma autoimagem que valorizava seus cabelos, cor da pele, lábios. Uma outra estudante escreveu em seu desenho: "Respeite a minha história!". É interessante observarmos que a despeito da escola não tratar de maneira transversal questões relacionadas à história e cultura afro-brasileira, ela se faz presente por meio dos corpos e da estética das crianças e jovens negras. E nesse sentido, a partir destas contradições iniciais, estas atividades foram fundamentais para que as estudantes se orientassem ao longo da estada com a turma ao longo do PIBID. 
O "Projeto VOARTE - Nas asas da Arte Educação" foi uma das ações que possibilitou uma significativa participação das bolsistas e dos bolsistas. Trata-se de um projeto da Rede Municipal de Ensino de São Francisco do Conde, desenvolvido nas unidades escolares da Educação Infantil ao Ensino Fundamental e suas modalidades (Educação de Jovens e Adultos e Educação Especial) a partir das linguagens artísticas, com foco na leitura, visando fortalecer o processo de ensino e de aprendizagem, ampliar o repertório literário e artístico dos alunos, dos profissionais da Educação e da comunidade.

O objetivo do Projeto Voarte é desenvolver a leitura através da utilização de recursos e metodologias das linguagens artísticas, em diálogo com as demais áreas integrantes do Currículo. Nesse sentido, realizamos oficinas de contação de histórias com as crianças, utilizando diferentes recursos, com temáticas relacionadas a cultura afro-brasileira. (Estudante bolsista Escola Arlete Magalhães).

A literatura infanto juvenil possibilitou às bolsistas e aos bolsistas a atuação em sala de aula de várias formas e aqui destacamos a iniciativa da Escola Frei Eliseu Eismam que estabeleceu uma carga horária semanal para a atuação das/os discentes bolsistas em sala de aula. Como a escola havia desativado a biblioteca transformando-a em sala de aula, a orientação era que estes momentos pudessem ser usados para contação de história e atividades decorrentes.

Outra atividade que envolveu a participação das bolsistas e dos bolsistas a partir da literatura infanto juvenil foram as Sessões Simultâneas de Leitura, momento em que todas as escolas da rede municipal param para que as crianças ouvissem histórias, através do Projeto "Semeando Leitores". Os relatos abaixo nos permitem inferir que seja pela contação de história ou por meio da dança, as vivências de leitura atravessadas por diferentes linguagens, possibilitaram momentos de descontração junto com as crianças. Ao tempo em que se expressam e se posicionam quanto a valorização da cultura negra como forma de identificação e resgate da autoestima, de forma lúdica e criativa, desenvolvendo um olhar mais crítico sobre a sociedade em que estão inseridas. Os relatos das bolsistas revelam:

Para fazer a leitura de Pretinha de Neve e os 7 Gigantes levei uma boneca de pano que eu tinha feito há um tempo atrás. Pensei que seria interessante levar uma boneca preta para terem contato. A leitura transcorreu bem, apesar de o texto ser um pouco longo e a turma, por não estar acostumada com a leitura assim, ter se cansado um pouco. A boneca parece ter chamado atenção! Ao final da leitura as meninas pediram para ver e tocar na boneca, agora batizada de Pretinha! [...] Depois de acabar nossos trabalhos, quando eu estava sentada no chão 
fazendo o cartaz, duas estudantes pediram para brincar com Pretinha. Abraça daqui, beija dali e uma delas pergunta se a Pretinha da história era mesmo uma menina preta. Eu respondi que sim. Ela ficou em silêncio. Essa estudante não se desenha como uma menina negra e nem em suas histórias - ao menos nas que eu ouvi - ela coloca personagens negros. (Estudante bolsista - Escola Frei Eliseu Eismann).

Uma atividade que merece destaque foi a oficina de dança Afrohouse, como uma prática pedagógica que estimula a criatividade, além de favorecer o processo de construção do conhecimento, através deste gênero musical de origem angolana. Os educandos que participaram desta sessão de leitura conheceram um pouco da cultura dos povos angolanos através desse ritmo que envolve movimentos dos pés, quadris e troncos. (Estudante bolsista - Escola Frei Eliseu Eismann).

A criação de espaços e momentos de interlocução com as crianças, permitindo-as falarem, conversarem e (re)criarem suas histórias, enquanto protagonistas, respeitando "as diferentes formas de expressão e fala, que lhes dão marca de pertencimento às culturas e aos mundos plenos de valores e de sentidos, historicamente produzidos e socialmente marcados [...]" (SARMENTO; VASCONCELLOS, 2007, p. 09), permite a valorização da cultura africana e afrobrasileira contribuindo na construção identitárias das educandas e educandos. Cabe salientar que neste contexto, fica evidente para as professoras regentes, a importância de trabalhar valores da cultura africana e afro-brasileira, com vistas a ressignificar conteúdos pautados em um currículo eurocentrado.

Comecei a oficina com a dinâmica Raízes, criada por mim, para acalmar o grupo e dar o sentido de unidade que guiará o pensamento acerca da nossa identidade afro-brasileira. Após, ao começar a contar a história da boneca, alguns meninos e meninas disseram já ter visto como se faz a boneca na televisão, acredito que no TV Escola, se não estou enganada. Assim, pedi que me auxiliassem no processo de contar a história para as demais crianças. Dois meninos, cujos nomes não me lembro ao certo, me chamaram bem atenção. Ambos bem articulados e com um bom desenvolvimento de raciocínio, um parecia gostar muito de História e o outro também, com especial atenção para África e sua ligação com o Brasil. (Estudante bolsista - Escola Frei Eliseu Eismann).

A inserção no espaço escolar trouxe muitos desafios e expectativas para os estudantes bolsistas. Um encontro com a realidade e o conhecimento deste ambiente, onde novos aprendizados se descortinam e relações são construídas. Destacam que a possibilidade de um contato mais próximo com o universo das escolas públicas e com situações da prática profissional foi o fator essencial para a formação docente inicial. E acrescentam que embora a escola venha buscando 
trabalhar em uma perspectiva mais inclusiva, as lacunas e fragilidades são visíveis; o que demanda um esforço coletivo para a superação.

As relações estabelecidas entre os diferentes atores e atrizes das comunidades escolares, permitiram a apreensão de comportamentos e ações que subsidiaram o planejamento das atividades a serem desenvolvidas com as crianças. As dificuldades de algumas alunas e alunos quanto ao acesso a condições adequadas de moradia, alimentação, saúde e higiene, foram vistos como fatores que influenciam a forma como estes atuam em sala de aula, seus comportamentos e aquisição de conhecimento. Um fator comumente apontado pela escola é a ausência de diálogo com as famílias, não encontrando ajuda na mediação de certos comportamentos que comprometem suas aprendizagens. Segundo as estudantes o que a escola parece não querer ver sem estereotipar é a realidade de cada uma e cada um. O que se apresenta como um desafio frente ao trabalho desenvolvido com turmas diferentes e a subjetividade de cada criança.

Um dos assuntos mais comentados do momento foi a higiene do aluno. É sintomático perceber que somente a higiene de um aluno negro foi tida como assunto, quando na turma temos também alunos brancos que sempre vão com roupas sujas para a escola e não foram sequer citados. Sem a menor sensibilidade chegaram a sugerir que se trabalhasse o tema da higiene com o Cascão e o Cebolinha. Será que não perceberam que o Cascão é o único personagem negro da turma da Mônica e o único que não gosta de banho? (Estudante bolsista - Escola Frei Eliseu Eismann).

A intransigência em relação aos corpos negros e a passividade e compreensão em relação aos brancos é comum no imaginário social e educacional brasileiro. Corpos negros são marginalizados, sexualizados, demonizados necessitando uma "adequação" pautada no ideal de civilidade, o corpo branco. Corpos brancos não carecem ser pensando, posto que dentro dessa perspectiva são a regra a ser seguida. Torna-se premente descortinar as ações e práticas coloniais e, portanto, racistas, que organizam as relações sociais, sob pena de, ao não fazê-lo, continuar engendrando ações de marginalização e exclusão de pessoas negras da escola.

As experiências desenvolvidas por meio do PIBID possibilitaram as/aos estudantes reflexões sobre o processo de formação, o qual transcende espaços formais, favorecendo não só a compreensão de certos fenômenos educativos, mas também uma (auto)reflexão, podendo vir a contribuir no aprimoramento e coerência entre a teoria e a prática. Nesta esteira, a aplicação de estratégias pedagógicas voltadas a Lei 10.639/03, abriu espaço para a ressignificação da identidade negra nas escolas que, a partir da valorização de culturas e costumes 
de um povo que por tanto tempo foi impedido de se expressar e de se reconhecer na sociedade.

\section{TECENDO CONSIDERAÇÕES FINAIS}

A experiência de formação possibilitada pelo PIBID, por meio de atividades docentes, em diferentes contextos da prática pedagógica, foi determinante para a ampliação de conhecimentos das estudantes e dos estudantes bolsistas, bem como das professoras regentes. A temática favoreceu ainda momentos de grandes aprendizagens nas reuniões de planejamento fazendo dos encontros semanais espaços de trocas interpessoais. Tais momentos inspiraram acadêmicos e futuros professores a exporem suas ideias de modo claro, desmistificando os preconceitos e os temores de se falar e se pensar aspectos relacionados à cultura africana e afro-brasileira, à população negra, embora essas discussões ainda possam ser consideradas como tabus no ambiente e nas práticas escolares e acadêmicas.

O PIBID tem construído nas acadêmicas e nos acadêmicos uma nova perspectiva de docente, promovendo práticas e métodos de ensinoaprendizagem com sentido e significado, diversificando a maneira de trabalhar com os mais diferentes conteúdos e tornando o aluno e a aluna parte fundamental do processo de elaboração de seu próprio conhecimento. A realização deste tipo de ações na escola torna-se fundamental quando se pretende atuar na elaboração de propostas educativas a partir da Leil 10.639/03, promovendo a valorização e reconhecimento da cultura afro-brasileira e uma educação antirracista.

As atividades possibilitaram que os(as) bolsistas do PIBID, revelassem para os alunos que os africanos fazem parte da história brasileira, ao reconhecerem a riqueza da cultura afro, que foi trazida para o Brasil junto com os africanos. Assim, conforme Freire (2013, p. 40)“[...] na formação permanente dos professores, o momento fundamental é o da reflexão crítica sobre a prática. É pensando criticamente a prática de hoje ou de ontem que se pode melhorar a próxima prática". É esse movimento que estamos buscando problematizar nossas práticas, assim como os discursos sobre ela, a teoria em que se baseia, para nos construirmos como sujeitos e professores críticos e reflexivos.

Outro fator importante a se destacar e que revela a grandeza da realização de projetos PIBID em uma universidade pluriétnica e pluricultural como a UNILAB foi a participação de estudantes africanas e africanos como bolsistas do projeto, o que possibilitou que estudantes da educação básica, bem como professoras e professores e toda a comunidade escolar repensassem os estereótipos comuns associados à realidade africana e aos africanos e africanas 
que hoje moram na cidade de São Francisco do Conde por estudarem na UNILAB.

Um dos desafios à formação inicial e continuada de professoras e professores é possibilitar o aprofundamento de saberes e conhecimentos outros, pautados pela diferença e pela multiplicidade cultural brasileira de forma a instrumentalizar as ações em sala de aula. Possibilitando não somente o ensino sobre a história da África e do povo negro e indígena, mas sobretudo, colocando como centralidade grupos sociais marginalizados e construindo juntos outros caminhos para uma educação antirracista e livre das amarras epistemológicas que subalternizam e excluem aqueles e aquelas que não são considerados iguais.

\section{REFERÊNCIAS}

ALVES, Maria Kellynia Farias. A didática afrorreferenciada entra na roda: experiências com EJA e formação de professores. VII Artefatos da Cultura Negra, Universidade Regional do Cariri, set. 2016. Disponível em: http://www.repositorio.ufc.br/bitstream/riufc/29941/3/2016_eve_mkfalves.pdf.

BALL, Stephen J; MAGUIRE, Meg; BRAUN, Annette. Como as escolas fazem políticas: atuações em escolas secundárias. Ponta Grossa: UEPG, 2016.

BOGDAN, R.; BIKLEN, S. Investigação qualitativa em educação: uma introdução à teoria e aos métodos. Porto: Porto Editora, 1994.

BRASIL. Conselho Nacional de Educação. Parecer CNE/CP 009/2001, de 8 de maio de 2001a. Diretrizes Curriculares Nacionais para a Formação de Professores da Educação Básica, em nível superior, curso de licenciatura, de graduação plena. Diário Oficial da União, Brasília, DF, 18 de jan. 2002. seção 1. p. 31. Disponível em: Disponível em: http://portal.mec.gov.br/cne/arquivos/pdf/009.pdf . Acesso em: 3 mar. 2004.

BRASIL. Decreto no 7.219, de 24 de junho de 2010. Dispõe sobre o Programa Institucional de Bolsa de Iniciação à Docência - PIBID e dá outras providências. Brasília, DF, 2010.

CANDAU, Vera Maria. Sociedade Multicultural e Educação: tensões e desafios. In: CANDAU, Vera Maria (org.). Didática Crítica Intercultural aproximações. Ed. Vozes. 2012.

DEIMLING, Natalia Neves Macedo; REALI, Aline Maria de Medeiros Rodrigues. PIBID: considerações sobre o papel dos professores da educação básica no processo de iniciação à docência. Educação em Revista. Belo Horizonte, v.36, 2020. Disponível em: https://www.scielo.br/pdf/edur/v36/1982-6621-edur-36-e222648.pdf. Acesso em: 30 set.2020.

DEMO, Pedro. Desafios Modernos da Educação. 26. ed. São Paulo: Vozes, 2009. 
FREIRE, Paulo. Pedagogia da autonomia: saberes necessários à prática educativa. 46. ed. Rio de Janeiro: Paz e Terra, 2013.

GOMES, Nilma Lino. Trajetórias escolares, corpo negro e cabelo crespo: reprodução de estereótipos ou ressignificação cultural?. Revista Brasileira de Educação. no 21 . 2002.

GOMES, Nilma Lino. O Movimento Negro Educador: saberes construídos nas lutas por emancipação. Petrópolis, Rj: Vozes, 2017.

JOSSO, Marie Christine. Experiências de vida e Formação. São Paulo: Cortez, 2004.

MUNANGA, Kabengele (org.). Superando o Racismo na Escola, 2ª edição.

Ministério da Educação, Secretaria da Educação e Diversidade, 2005.

NÓVOA, Antonio (Org.). Profissão professor. Porto: Porto Editora, 1995.

NÓVOA, Antonio. O regresso dos professores. Pinhais: Melo, 2011.

OLIVEIRA, Dalila de Andrade. Gestão Democrática da Educação: Desafios Contemporâneos. 7ª̣ edição. Petrópolis, RJ. Vozes, 2007.

PETIT, Sandra. Pretagogia: Pertencimento, Corpo-dança afroancestral e Tradição oral: Contribuições do Legado Africano para a Implementação da Lei nº 10.639/03. Fortaleza: EdUECE, 2015.

SARMENTO, Manoel; VASCONCELLOS, Vera Maria Ramos de. Infância (in)visível. Araquara: Junqueira \&Marin, 2007.

SILVA, Ana Lúcia G.; ALMEIDA, Carla Verônica A.; JESUS, Joselito Manuel. Os Desafios da Educação Básica na contemporaneidade: diversidade, docência e identidades. In: ANAIS X SEMINÁRIO INTERNACIONAL DA REDE ESTRADO Direito à educação, políticas educativas e trabalho docente na América Latina: experiências e propostas em disputa. Salvador, 2014. v. 01. p. 1-15-558.

SILVA, Claudilene Maria da. A volta inversa na árvore do esquecimento e nas práticas de branqueamento: práticas pedagógicas escolas em história e cultura afrobrasileira. Curitiba: CRV, 2019.

TARDIF, Maurice. Saberes docentes e formação profissional. 9. ed. Petrópolis, RJ: Vozes, 2008.

UNESCO, MEC. Contribuição para Implementação da Lei 10.639/2003. Brasília, 2008. 